\title{
Fatigue life prediction of composite material's adhesive joints in automotive applications
}

\author{
Wenlong Zhang \\ Civil Engineering, \\ University of Cincinnati, \\ Cincinnati 45220, OH, USA \\ Email: zhang2w1@mail.uc.edu
}

\author{
Ala Tabiei* \\ Mechanical Engineering, \\ University of Cincinnati, \\ Cincinnati 45220, OH, USA \\ Email: tabieia@ucmail.uc.edu \\ *Corresponding author
}

\begin{abstract}
Composite and adhesive joints are used increasingly in the automotive industry, not only because of the government policy but also their advantages in mechanical properties over traditional materials and joints. An active research area is the fatigue analysis of adhesive joints. In this paper, a methodology to predict the fatigue life of adhesive joint is proposed and implemented into LS-DYNA with the joint modelled using a user-defined cohesive material. Fatigue crack growth rate is used to obtain the fatigue damage accumulation rate in cohesive zone model. Our method is verified by numerical simulations of two commonly used adhesive joints in the automotive industry: single-lap joint and stepped-lap joint. The predicted S-N curve fits well with the experimental data.
\end{abstract}

Keywords: adhesive joint; automotive; cohesive zone model; damage; Fatigue crack growth rate; LS-DYNA.

Reference to this paper should be made as follows: Zhang, W. and Tabiei, A. (2017) 'Fatigue life prediction of composite material's adhesive joints in automotive applications', Int. J. Automotive Composites, Vol. 3, No. 1, pp.61-79.

\begin{abstract}
Biographical notes: Wenlong Zhang is a PhD student at the University of Cincinnati, majoring in Civil Engineering. His research is about fracture and fatigue simulation using finite element method. He was awarded a BS in Beijing University of Civil Engineering and Architecture in 2013 and then continued to pursuing a PhD degree at the University of Cincinnati Experience: He has been a research assistant at UC simulation centre since 2013. The main work he has been doing is using FE simulation to help R\&D for a famous company in Cincinnati. His publications include Evaluation of Various Numerical Methods in Large Scale FE Simulation Codes for 3D Crack Propagation, Ala Tabiei, Wenlong Zhang (2016), International Journal of Structural Mechanics and Finite Elements, 1:2.
\end{abstract}


Professor Ala Tabiei has been with the department of Aerospace Engineering and Engineering Mechanics at the University of Cincinnati since September of 1995. He was the director of the Centre of Excellence in DYNA3D Analysis (1997-2001). He has a BS in Mechanical Engineering, a MS in Aeronautical Engineering, a MS in Mathematics and a Ph.D. (1994) in Aerospace Engineering from the University of Cincinnati. He has many years of crashworthiness and impact simulation experience using the finite element method at the US Department of Transportation and the automotive industry. His primary research focus is in the area of non-linear finite-element applications and material model development for isotropic and composite materials. He teaches several courses in linear and non-linear static and impact dynamic finite elements at the University of Cincinnati. He is a consultant to many companies in the USA and abroad on the use of large-scale finite element for multi-physics simulations. Dr. Tabiei's expertise is in the area of computational mechanics and numerical simulation.

\section{Introduction}

Adhesive joints have been used intensively in the aerospace industry since the early 1970s (Banea and da Silva, 2009) due to their advantages over traditional joints like welded and bolted joints. The application of adhesive joints in the automotive industry is also increasing significantly in recent years, both because of its attractive properties and the government policies. European Union's law requires new cars' $\mathrm{CO}_{2}$ emission to not exceed $130 \mathrm{~g} / \mathrm{km}$ by the year of 2015 , and that requirement is further reduced to $95 \mathrm{~g} / \mathrm{km}$ by 2021 , which is $27 \%$ of reduction (Parliament, 2009). A similar requirement is given by US government's corporate average fuel economy (CAFE) (Bastani et al., 2012). CAFE's standard requires more fuel efficiency and less greenhouse gas emission. Since reducing weight is an efficient way to increase fuel efficiency and reduce $\mathrm{CO}_{2}$ emission, the automotive industry is pushing the use of composites and adhesive joints due to their light weight.

Composite material is made by combining two or more constituent materials, usually fibres or particles into matrix. It can provide a combination of the mechanical properties of its substituents and thus achieve some purpose that single material cannot, like low weight and high strength. When used in automotive industry, apart from the weight saving advantage, it also provides more resistance to corrosion, more noise reduction, more energy absorption capability and higher styling flexibility (Friedrich and Almajid, 2013). As the manufacturing technique goes up and the cost goes down, composite material is used more and more in the bumper system (Mansor et al., 2014a), the brake structure (Mansor et al., 2014b), the noise-eliminating and soundproofing systems (Kim et al., 2013) and even in some loading-carrying body structures (Liu et al., 2013). Some commonly used composite materials are carbon fibre-reinforced plastic (CFRP) and glass fibre-reinforced plastic (GFRP). Researches are being done to improve the manufacturing and fabrication technique to make them more economical for industrial applications (Svensson et al., 2016; Banea et al., 2016). And at the same time, intensive studies are carried out to better understand composites' mechanical properties, like crashworthiness (Jacob et al., 2002, 2004), static and dynamic response of various adhesive joints (Kumar et al., 2006; Grant et al., 2009) and fatigue failure of composite and adhesive joints (Casas-Rodriguez et al., 2008; Varvani-Farahani et al., 2007). 
Adhesive joint can not only be used between composite materials but also be used to connect composite to metal and metal to metal. It has the advantage of lower weight, lower fabrication cost, eliminating stress concentration, increasing corrosion resistance and more design flexibility. It also increases the overall stiffness of the body because of its continuous nature, thus enabling thinner materials to be used (Kadioglu and Adams, 2015). In structural applications, adhesive joints are primarily designed to carry shear load. Thus the commonly used adhesive joint types are single-lap joint, double lap joint, strapped joint and compound joint (Kuczmaszewski and Bylica, 2006).

Despite all these advantages of adhesive joints, there remains a concern in the industry that is the long-term service life under cyclic loading conditions. Prediction of fatigue life is especially important for parts near the engine where vibration is intense. Prediction needs to be made about the fatigue life of adhesive joint so a replacement can be done before that part fails. A large amount of research has been done in this area (Harris and Fay, 1992; Hadavinia et al., 2003; Quaresimin and Ricotta, 2006; Pang et al., 2013; Vucko et al., 2016). Apart from the experimental studies about the influence of various factors like temperature (Banea and da Silva, 2010), adhesive thickness (Azari et al., 2014), vibration frequency (Du and Shi, 2014) and load ratio (Pirondi and Nicoletto, 2004), a substantial amount of numerical studies also emerges to predict the fatigue life of adhesive joints (Roe and Siegmund, 2003; Turon et al., 2007; Harper and Hallett, 2010; Landry and LaPlante, 2012). Most of them use the cohesive zone model combined with fracture mechanics and damage mechanics to simulate fatigue accumulation. Roe and Siegmund (2003) proposed a damage evolution law to predict fatigue accumulation. In his model, damage accumulation rate is calculated using deformation rate, endurance limit and accumulated separation. By integrating the damage accumulation rate over time, the amount of damage is obtained and used to decrease the cohesive strength. Roe's damage evolution law provides an insight into how damage mechanics can be utilised for fatigue analysis but also suffers from the high computational cost when, it is high cyclic loading because a history of deformation rate is needed for damage calculation.

When it comes to high cyclic loading, a commonly used approach is to combine damage accumulation with fracture toughness and fatigue crack growth rate (FCGR), which is often characterised by Paris law (Pugno et al., 2006). Paris law defines the relationship between crack propagation rate and fracture toughness range, as shown in Eq. (1).

$$
\frac{\mathrm{d} a}{\mathrm{~d} N}=D(\Delta K)^{B}, \text { where } \Delta K=K_{\max }-K_{\min }
$$

where $a$ is the crack length and $N$ is the number of loading cycles. $D$ and $B$ are curvefitting parameter of experiment data, and they can be considered as material parameters. Since correlation can be found between energy release rate and fracture toughness, Paris law can also be expressed in terms of energy release rate change (Eq. 2), as shown in Figure 1.

$$
\frac{\mathrm{d} a}{\mathrm{~d} N}=C(\Delta G)^{m}, \text { where } \Delta G=G_{\max }-G_{\min }
$$


Figure 1 Typical Paris law

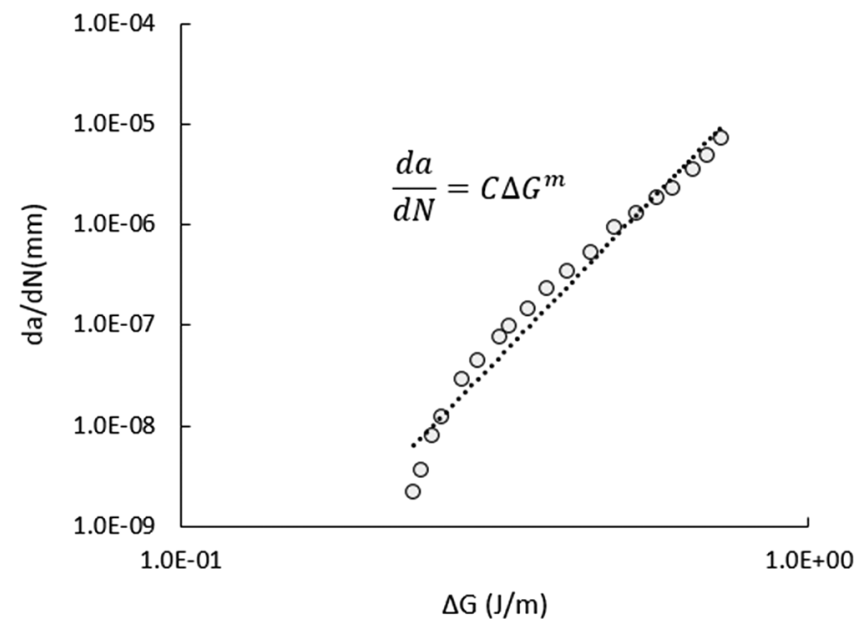

After the Paris law relationship is defined by experiment, the FCGR can be implemented into finite-element scheme with the help of cohesive zone model, and this will be described in detail in Section 2.

Cohesive zone model was proposed by Dugdale (1960) and Barenblatt (1962) to handle the process zone near the crack tip (Figure 2). It describes the traction-separation relationship between two surfaces before they are formed. The traction-separation relationship is often called cohesive law, and it can have various shapes like bilinear, trilinear and exponential form. The area under traction-separation curve corresponds to the critical energy release rate it takes to create a new pair of surfaces. Cohesive zone model is often implemented with cohesive elements, which can have small and even zero thickness without reducing the critical time step. That is because only stiffness and mass are used to obtain the time step. This feature gives it advantages in modelling adhesives whose thickness is usually very small. A detailed formulation about cohesive element can be found in Camanho and Dávila (2002).

Figure 2 Illustration of cohesive zone model and different cohesive laws
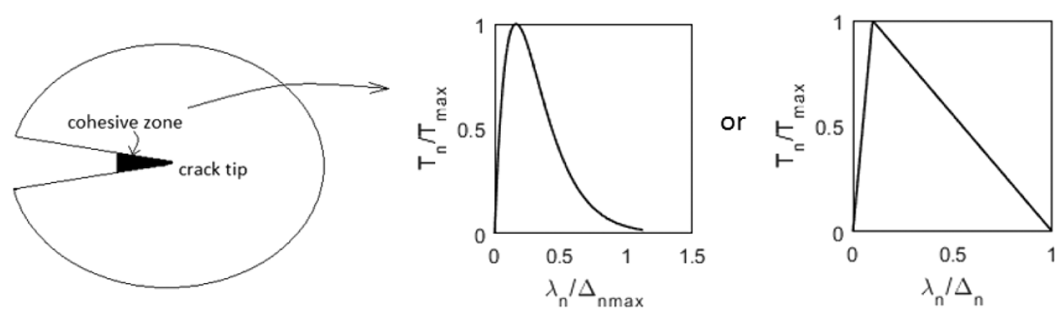

For high cyclic fatigue, it would take a significant number of loading cycles before it reaches the failure point, which means the total period of the experiment would be so long that explicit time integration is almost impossible. Algorithms like cyclic jump method, linear extrapolation method has been proposed by authors to reduce the high computational cost. Particular caution is needed when using these methods, because cyclic jump needs to be limited to guarantee the accuracy. A better choice is to use 
implicit time integration combined with these algorithms, because it is unconditionally stable and the time step can be as big as needed. However, cohesive laws have a turning point in the traction-separation curve, and it makes it hard to achieve convergence, and some techniques like arc length method (Crisfield, 1983) and viscous regularisation (Yu et al., 2016) need to be used to overcome that difficulty.

In this paper, a method to predict fatigue life using FCGR and cohesive model is proposed. The joint is modelled using a user-defined cohesive material model. Implicit time integration scheme is used, and viscous regularisation algorithm is programed within the user-defined material model to help convergence. This cohesive damage model is used to predict S-N curve of single-lap adhesive joint and stepped-lap adhesive joint, which is commonly utilised in the automotive industry. This paper is organised as follows: In Section 2, the methodology and its implementation into LS-DYNA are presented; In Section 3, two numerical simulations are carried out to verify our proposed method. Paris law parameters used in our simulation are obtained from experiments in the literature.

\section{Combining fatigue crack growth rate (FCGR) with cohesive zone model}

The approach of combining FCGR with cohesive zone model is not new and has been used by several authors (Turon et al., 2007; Harper and Hallett, 2010; Landry and LaPlante, 2012). Turon et al. $(2006,2007)$ derived overall damage accumulation rate $\dot{d}$ from the relationship of total damage parameter $d=d_{s}+d_{f}$ and the area covered by cyclic loading curve in traction-separation law. Harper and Hallett (2010) derived fatigue damage accumulation rate $\dot{d}_{f}$ by proposing a concept of fatigue crack length across the element and Landry and LaPlante (2012) used the same concept to derive fatigue damage accumulation rate. These papers provide an insight for relating the $\dot{d}_{f}$ to FCGR. These models were proposed for delamination fatigue analysis, where at the crack tip cohesive elements are at the descending part of the cohesive law, so these models did not account for the fatigue accumulation when it is in the ascending part of the cohesive law. For adhesive joint, however, when at service load, it should be way below the ultimate strength for most part of adhesive joint, it is in the elastic ascending part of cohesive law. Thus, the fatigue accumulation during that period, although not much, should also be considered when modelling adhesive joints. And that issue is addressed in this paper. In our method, different from other authors, a new way of relating FCGR to damage parameter is used, and after the damage parameter is obtained, it is used to reduce the critical energy release rate in cohesive zone model. Bilinear cohesive law is used as it is straightforward and robust in cyclic loading.

\subsection{Bilinear cohesive law}

Bilinear cohesive law by Camanho et al. (2003) uses a mixed mode criterion to combine mode I and II loading into mixed mode loading and to guarantee the continuity of traction-separation curve under arbitrary cyclic loading (Figure 3). For cohesive law, mode I loading corresponds to loading in the normal direction of the surface, and mode II loading corresponds to the tangential loading on the surface. If fatigue is not considered, 
only static damage parameter will be calculated to reduce the stiffness. The static damage parameter is expressed in Eq. (3) (Livermore software technology corporation, 2013).

$$
d_{s}=\min \left(\frac{\Delta^{F}}{\lambda_{\max }} \frac{\lambda_{\max }-\Delta^{0}}{\Delta^{F}-\Delta^{0}}, 1\right)
$$

Figure 3 Illustration of bilinear cohesive law (see online version for colours)

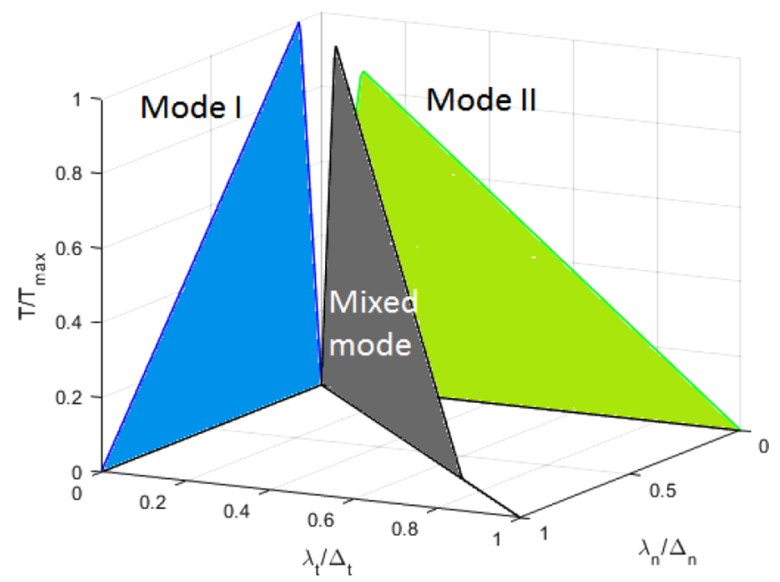

where

$$
\begin{aligned}
& \Delta^{0}=\Delta_{\mathrm{I}}^{0} \Delta_{\text {II }}^{0} \sqrt{\frac{1+\beta^{2}}{\left(\Delta_{\mathrm{II}}^{0}\right)^{2}+\left(\beta \Delta_{\mathrm{I}}^{0}\right)^{2}}} \\
& \Delta^{F}=\left\{\begin{array}{cc}
\frac{2\left(1+\beta^{2}\right)}{\Delta^{0}}\left[\left(\frac{\mathrm{EN}}{G_{\mathrm{IC}}}\right)^{\alpha}+\left(\frac{\mathrm{ET} \beta^{2}}{G_{\mathrm{IIC}}}\right)^{\alpha}\right]^{-1 / \alpha} & \lambda_{\mathrm{I}}>0 \\
\frac{2 G_{\mathrm{IIC}}}{S} & \lambda_{\mathrm{I}} \leq 0
\end{array}\right. \\
& \Delta_{I}^{0}=T / \mathrm{EN} \\
& \Delta_{I I}^{0}=S / \mathrm{ET}
\end{aligned}
$$

In these equations, $\Delta^{F}$ represents the mixed-mode separation exceeds which the cohesive zone will fail; $\Delta^{0}$ represents the mixed mode separation that corresponds to the maximum traction; $\lambda_{\max }=\sqrt{\lambda_{1}^{2}+\lambda_{\mathrm{II}}^{2}}$ is the maximum mixed mode separation within a loading cycle; $\beta=\lambda_{\mathrm{II}} / \lambda_{\mathrm{I}}$ is the mixed mode ratio, in which $\lambda_{\mathrm{I}}$ is the separation in normal direction and $\lambda_{\text {II }}$ is the separation in tangential direction; $T$ and $S$ are the cohesive strength in normal and tangential direction, respectively; EN and ET are the initial stiffness in normal and tangential direction, respectively; $G_{\text {IC }}$ and $G_{\text {IIC }}$ are the critical energy release rate in mode I and II respectively. $\alpha$ in Eq. (5) is an adjustable 
parameter defined by users and if it is taken as 1 , which means a linear law is used to combine mode I and II deformation, Eq. (3) becomes:

$$
\Delta^{F}=\left\{\begin{array}{cl}
\frac{2\left(1+\beta^{2}\right)}{\delta^{0}}\left[\left(\frac{\mathrm{EN}}{G_{\mathrm{IC}}}\right)+\left(\frac{\mathrm{ET} \beta^{2}}{G_{\mathrm{IIC}}}\right)\right]^{-1} & \lambda_{\mathrm{I}}>0 \\
\frac{2 G_{\mathrm{IIC}}}{S} & \lambda_{\mathrm{I}} \leq 0
\end{array}\right.
$$

After the static damage parameter $d_{s}$ is defined, tractions in normal and tangential direction can be defined as:

$$
\begin{aligned}
& T_{n}=\left\{\begin{array}{cc}
\mathrm{EN} \times\left(1-d_{s}\right) \times \lambda_{\mathrm{I}} & 0<\lambda_{\mathrm{I}}<\Delta^{F} \\
\mathrm{EN} \times \text { Scale Factor } \times \lambda_{\mathrm{I}} & \lambda_{\mathrm{I}}<0
\end{array}\right. \\
& T_{t}=\mathrm{ET} \times\left(1-d_{s}\right) \times \lambda_{\mathrm{II}}
\end{aligned}
$$

When fatigue damage factor $d_{f}$ is considered, we need to consider its influence on the damage parameter and it will become $d=d_{s}+d_{f}$ and Eqs. (9-10) becomes:

$$
\begin{aligned}
& T_{n}=\left\{\begin{array}{cc}
\mathrm{EN} \times\left(1-d_{s}-d_{\mathrm{f}}\right) \times \lambda_{\mathrm{I}} & 0<\lambda_{\mathrm{I}}<\Delta^{F} \\
\mathrm{EN} \times \text { Scale Factor } \times \lambda_{\mathrm{I}} & \lambda_{\mathrm{I}}<0
\end{array}\right. \\
& T_{t}=\mathrm{ET} \times\left(1-d_{s}-d_{f}\right) \times \lambda_{\mathrm{II}}
\end{aligned}
$$

The effect of fatigue damage on Eqs. (11-12) can be illustrated in Figure 4.

Figure 4 Illustration of fatigue effect on bilinear cohesive law (see online version for colours)

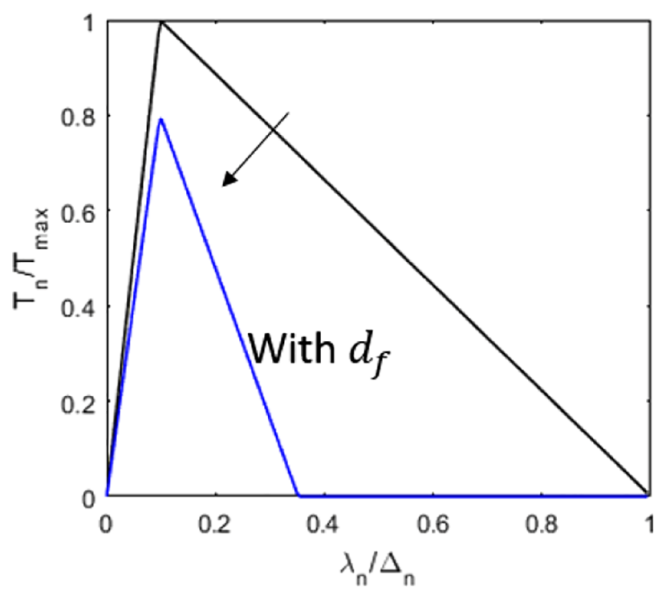

\subsection{Damage accumulation rate}

As stated in the previous sub-section, when fatigue is considered, the damage parameter becomes $d=d_{s}+d_{f}$. Since static damage parameter $d_{s}$ will not change with cyclic 
loading, the main objective becomes to calculate $d_{f}$ by integrating the fatigue damage accumulation rate $\dot{d}_{f}$ over time. Inspired by Turon's approach (Turon et al., 2007), we use the ratio between damaged area to the overall area in an element $A_{d} / A_{e}$ to obtain $\dot{d}_{f}$. When an element is in the cohesive zone, $A_{d} / A_{e}$ can be represented in Eq. (13):

$$
\frac{A_{d}}{A_{e}}=\frac{S+F}{G_{c}-R}
$$

where $S, F$ and $R$ are the areas under cohesive law illustrated in Figure 5a. $S$ represents the static damage, and $F$ accounts for the fatigue damage.

$$
\begin{aligned}
& S=\frac{1}{2} E \Delta_{0} \Delta_{f}-\frac{1}{2} E\left(1-d_{s}\right) \lambda \Delta_{f} \\
& G_{c}=\frac{1}{2} E \Delta_{0} \Delta_{f} \\
& R=\frac{1}{2} E\left(1-d_{s}\right) \lambda\left(\Delta_{f}-\lambda\right) \\
& F=\frac{1}{2} E\left(1-d_{s}\right) \lambda^{2}-\frac{1}{2} E\left(1-d_{s}-d_{f}\right) \lambda^{2}
\end{aligned}
$$

Figure 5 Static and fatigue damaged area in cohesive law (a) when separation is at descending part and (b) when separation is at ascending part (see online version for colours)

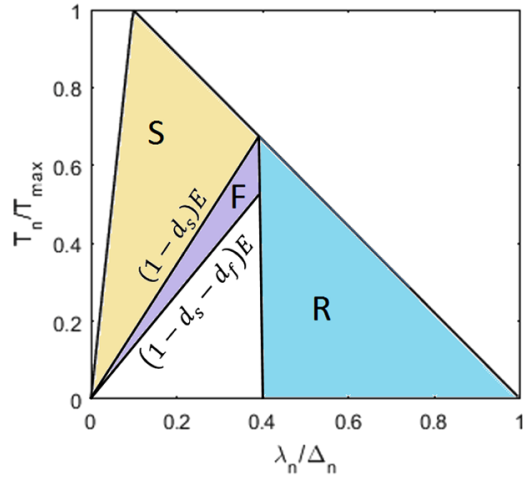

(a)

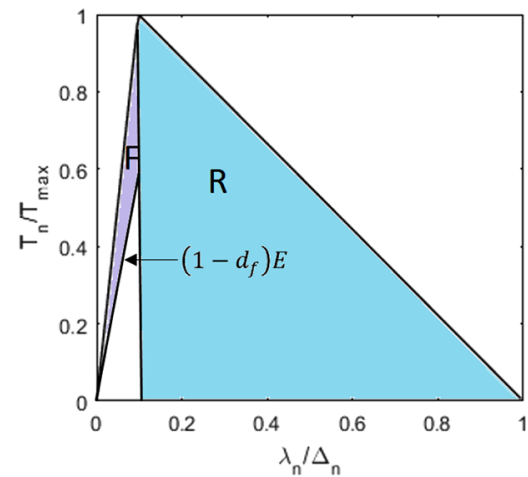

(b)

In Eq. (14-17), $E$ represents either EN or ET, depending on whether it is normal or tangential loading. $\Delta_{f}$ and $\Delta_{0}$ could also represent the characteristic separations in normal or tangential direction, in which $\Delta_{f}$ is the maximum allowable separation and $\Delta_{0}$ is the separation at maximum traction. Plug Eqs. (14-17) back to Eq. (13), we will get:

$$
\frac{A_{d}}{A_{e}}=\frac{\Delta_{0} \Delta_{f}-\left(1-d_{s}\right) \lambda \Delta_{f}+\left(1-d_{s}\right) \lambda^{2}-\left(1-d_{s}-d_{f}\right) \lambda^{2}}{\Delta_{0} \Delta_{f}-\left(1-d_{s}\right) \lambda\left(\Delta_{f}-\lambda\right)}
$$


where $\lambda$ is the separation in mixed mode. By ignoring the influence of fatigue accumulation on static damage parameter, the damage accumulation rate can be expressed as:

$$
\frac{\partial d}{\partial N}=\frac{\partial d}{\partial A_{d}} \frac{\partial A_{d}}{\partial N}=\frac{\partial\left(d_{s}+d_{f}\right)}{\partial A_{d}} \frac{\partial A_{d}}{\partial N}=\frac{\partial d_{f}}{\partial A_{d}} \frac{\partial A_{d}}{\partial N}=\frac{\partial d_{f}}{\partial N}
$$

From Eq. (18), we can get:

$$
\frac{\partial d_{f}}{\partial A_{d}}=\frac{1}{A_{e}} \frac{\Delta_{0} \Delta_{f}-\left(1-d_{s}\right) \lambda\left(\Delta_{f}-\lambda\right)}{\lambda^{2}}
$$

The increase of the damaged area along a crack front is equal to the sum of the damaged area increase of all the elements ahead of the crack tip. If the modelling of adhesive joint is using a constant element size, and since the damage at the crack front is approximately uniformly distributed through the width, we can assume that the damaged area of elements in cohesive zone is approximately the same, and the FCGR can be written as:

$$
\frac{\partial A}{\partial N}=\frac{A_{\mathrm{cz}}}{A_{e}} \frac{\partial A_{d}}{\partial N}
$$

where $A_{\text {cz }}$ is the cohesive zone size. For mode I case (Turon et al., 2006):

$$
A_{\mathrm{cz}, \mathrm{I}}=b \frac{9 \pi}{32} \frac{\mathrm{EG}_{\mathrm{IC}}}{T^{2}}
$$

Plug Eqs. (20-22) into Eq. (19), we can get:

$$
\frac{\partial d_{f}}{\partial N}=\frac{32 T^{2}}{b 9 \pi \mathrm{EG}_{\mathrm{IC}}} \frac{\Delta_{0} \Delta_{f}-\left(1-d_{s}\right) \lambda_{\mathrm{I}}\left(\Delta_{f}-\lambda_{\mathrm{I}}\right)}{\lambda_{\mathrm{I}}^{2}} \frac{\partial A}{\partial N}
$$

Assuming the adhesive joint has the same width across the section, it can be further simplified to:

$$
\frac{\partial d_{f}}{\partial N}=\frac{32 T^{2}}{9 \pi \mathrm{EG}_{\mathrm{IC}}} \frac{\Delta_{0} \Delta_{f}-\left(1-d_{s}\right) \lambda_{\mathrm{I}}\left(\Delta_{f}-\lambda_{\mathrm{I}}\right)}{\lambda_{\mathrm{I}}^{2}} \frac{\partial a}{\partial N}
$$

where $a$ is the crack length. Similarly, for mode II case the cohesive zone size can be approximated as: (Harper and Hallett, 2008)

$$
A_{\mathrm{cz}, \mathrm{II}}=\frac{b \mathrm{EG}_{\mathrm{IIC}}}{S^{2}}
$$

In mode II case, the fatigue damage accumulation rate $\dot{d}_{f}$ would be:

$$
\frac{\partial d_{f}}{\partial N}=\frac{S^{2}}{E G_{\mathrm{IIC}}} \frac{\Delta_{0} \Delta_{f}-\left(1-d_{s}\right) \lambda_{\mathrm{II}}\left(\Delta_{f}-\lambda_{\mathrm{II}}\right)}{\lambda_{\mathrm{II}}^{2}} \frac{\partial a}{\partial N}
$$

When it is at mixed-mode loading case, linear interpolation is used to get the equivalent cohesive zone length: 


$$
A_{\mathrm{cz}}=A_{\mathrm{cz}, \mathrm{I}}+\beta\left(A_{\mathrm{cz}, \mathrm{II}}-A_{\mathrm{cz}, \mathrm{I}}\right)
$$

where $\beta=\lambda_{\mathrm{II}} / \lambda_{\mathrm{I}}$ is the mixed-mode ratio. Then for mixed-mode separation $\dot{d}_{f}$ becomes:

$$
\frac{\partial d_{f}}{\partial N}=\frac{b}{A_{\mathrm{cz}}} \frac{\Delta_{0} \Delta_{f}-\left(1-d_{s}\right) \lambda\left(\Delta_{f}-\lambda\right)}{\lambda^{2}} \frac{\partial a}{\partial N}
$$

where $\lambda$ is the mixed-mode separation. Equations $\left(24,26\right.$ and 28) all represent the $\dot{d}_{f}$ expression when the separation is at the descending part of cohesive law.

For cases where separation is at the ascending part of cohesive zone $\left(0<\lambda<\Delta_{0}\right)$, like shown in Figure $5 \mathrm{~b}$, a similar approach is used to obtain $\dot{d}_{f}$. We have $d_{s}=0$ and

$$
\begin{aligned}
& \frac{A_{d}}{A_{e}}=\frac{F}{F+R}=\frac{\frac{1}{2} E \lambda^{2}-\frac{1}{2} E\left(1-d_{f}\right) \lambda^{2}}{\frac{1}{2} E \lambda^{2}}=d_{f} \\
& \frac{\partial d_{f}}{\partial A_{d}}=\frac{1}{A_{e}}
\end{aligned}
$$

For mode I:

$$
\frac{\partial d_{f}}{\partial N}=\frac{b}{A_{\mathrm{cz}, \mathrm{I}}} \frac{\partial a}{\partial N}=\frac{32 T^{2}}{9 \pi \mathrm{EG}_{\mathrm{IC}}} \frac{\partial a}{\partial N}
$$

For mode II:

$$
\frac{\partial d_{f}}{\partial N}=\frac{b}{A_{\mathrm{cz}, \mathrm{II}}} \frac{\partial a}{\partial N}=\frac{S^{2}}{E G_{\mathrm{IIC}}} \frac{\partial a}{\partial N}
$$

For mixed mode:

$$
\frac{\partial d_{f}}{\partial N}=\frac{b}{A_{\mathrm{cz}}} \frac{\partial a}{\partial N}
$$

After the relationship between damage accumulation rate and FCGR is determined, we can relate it to the FCGR:

$$
\frac{\partial a}{\partial N}=C(\Delta G)^{m}
$$

Parameters $C$ and $m$ for mode I and II can both be determined through experiment. The right-hand side of the equation is energy release rate change, which corresponds to the area under the traction-separation law as shown in Figure 6. If the load ratio is known, the energy release rate can be calculated using Eq. (35):

$$
\Delta G=\frac{1}{2 E}\left(T_{\max }^{2}-T_{\min }^{2}\right)=\frac{T_{\max }^{2}}{2 E}\left(1-R^{2}\right)
$$


Figure 6 Illustration of energy release rate change (see online version for colours)

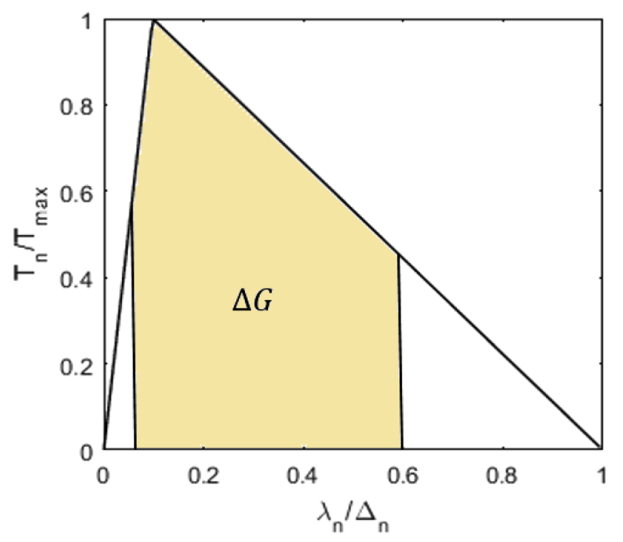

Regarding separation in normal and tangential direction, Eq. (35) can be represented as:

$$
\Delta G_{i}=\frac{E \lambda_{i}^{2}}{2}\left(1-R^{2}\right)\left(1-d_{s}\right)\left(1-d_{f}\right) \quad i=1,2
$$

where $i=1,2$ represents mode I and II, respectively. Mixed-mode energy release rate change is obtained by linear interpolation of mode I and II.

$$
\Delta G=\Delta G_{\mathrm{I}}+\beta\left(\Delta G_{\mathrm{II}}-\Delta G_{\mathrm{I}}\right)
$$

After that, linear interpolation is used to obtain the mixed-mode FCGR parameters:

$$
\begin{aligned}
& \ln (C)=\ln \left(C_{\mathrm{II}}\right)+\left[\ln \left(C_{\mathrm{I}}\right)-\ln \left(C_{\mathrm{II}}\right)\right]\left(1-\frac{G_{\mathrm{II}}}{G_{T}}\right) \\
& m=m_{\mathrm{I}}+\left(m_{\mathrm{II}}-m_{\mathrm{I}}\right)\left(\frac{G_{\mathrm{II}}}{G_{T}}\right)
\end{aligned}
$$

where $G_{T}=G_{\mathrm{I}}+G_{\mathrm{II}}$.

\subsection{Implementation of fatigue law into implicit time integration}

After the damage accumulation rate is determined, the fatigue damage parameter will be calculated by

$$
d_{f, n+1}=d_{f, n}+\frac{\partial d_{f}}{\partial N}
$$

For high cyclic loading where millions of cycles happen, it is computationally impossible to calculate fatigue damage cycle by cycle. Thus a cyclic jump method is used. It is assumed the damage accumulation rate within a range cycles are the same, then:

$$
d_{f, n+m}=d_{f, n}+m \frac{\partial d_{f}}{\partial N}
$$


Implicit time integration is used to reduce computational time further. The time step is taken as a relatively large value compared to loading period. If the period of the cyclic loading $\Delta T$ is the same throughout the simulation, then Eq. (41) can be replaced by:

$$
d_{f, i+1}=d_{f, i}+\frac{d t_{i}}{\Delta T} \frac{\partial d_{f}}{\partial N}
$$

where $i$ represents the count of time step. In this way, instead of applying cyclic loading, only the load envelop and load ratio $R$ need to be provided, like shown in Figure 7.

Figure 7 Cyclic loading and load envelope (see online version for colours)

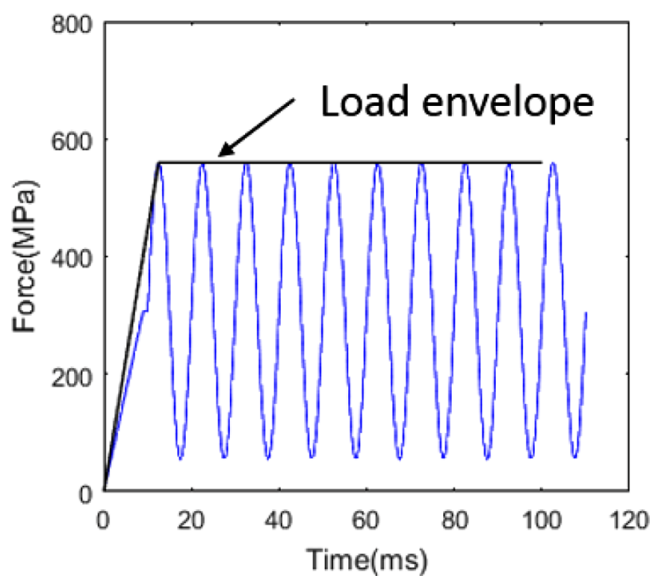

In implicit time integration, convergence could be hard to obtain when turning points exist in the material model, and this is the case with bilinear cohesive law. The arc-length method is used to help achieve convergence, and this is done by using the built-in algorithms in LS-DYNA. The keywords that help convergence in the input file can be found in Appendix A. Apart from the arc-length method, viscous regularisation method (Yu et al., 2016) is also used to help achieve convergence. In viscous regularisation, a viscous damage variable $d_{v}$ is introduced to replace the static damage variable $d_{s}$ :

$$
d_{v}=d_{s}-\eta \frac{\dot{\lambda}}{\lambda}
$$

where $\eta$ is a viscosity and is taken as $10^{-4}$ in our simulation. It helps convergence while limiting the viscous energy to a negligible range. Viscous regularisation is programed into UMAT41c in LS-DYNA to along with cohesive model.

\section{Numerical simulations}

Two simulation verifications are presented in this section to show the feasibility of our proposed fatigue accumulation method. Both simulations are to predict the S-N curves of commonly used adhesive joints in the automotive industry. FCGR parameters for the adhesive joints in mode I and II are obtained from the literature, which is obtained 
experimentally separately by other people. By doing this, we can verify the prediction ability of the proposed method.

\subsection{Single-lap joint glass fibre epoxy}

The first simulation is to validate the experiment done by Tang et al. (2013) on thick single-lap adhesive joint to test its fatigue behaviour. The adherent is glass fibrereinforced epoxy (GFRE), and the adhesive is epoxy. The specimen has a geometry shown in Figure 8, and the width of the specimen is $25 \mathrm{~mm}$. It is fixed at one end and stretched at the other end under cyclic loading (Figure 9) with a load ratio $R=0.1$ and a frequency of $5 \mathrm{~Hz}$. An illustration of material directions is also shown in Figure 9. The tensile modulus and Poisson's ratio of GFRE are summarised in Table 1 (Tang et al., 2013). An orthotropic elastic material property is used in the simulation and shear modulus are calculated using $G_{i j}=\frac{E_{i}}{4\left(1+v_{i j}\right)}+\frac{E_{j}}{4\left(1+v_{j i}\right)} \quad i, j=1,2,3$. The material properties of epoxy adhesive layer is summarised in Table 2 (Azari et al., 2010). The critical energy release rate $G_{\text {IIC }}$ and shear strength $S$ are assumed to be the same as $G_{\text {IC }}$ and $T$, respectively, as no information is provided from paper (Azari et al., 2010). Paris law parameters in mode I and II are taken from Brown et al. (2006) and O'Brien et al. (2010), respectively, and are used to predict the S-N curve (Figure 10). When single-lap joint is under tension, it has obvious peeling effect especially at edges, even though the adherent is very rigid. That peeling effect is verified by querying the tensile and shear stress along the adhesive joint when the tensile stress at ends are $8 \mathrm{MPa}$, and the stress distribution is compared to the FE simulation result (thickness $=2.5 \mathrm{~mm}$, $y / t_{a}=0.5$ ) in (Tang et al., 2013), as shown in Figure 11.

Figure 8 Geometry of GFRE single-lap joint specimen

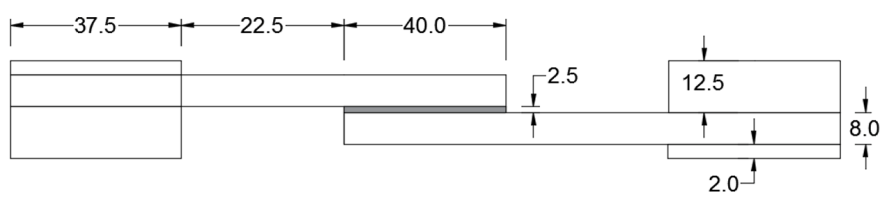

Figure 9 Load boundary condition of GFRE single-lap joint specimen

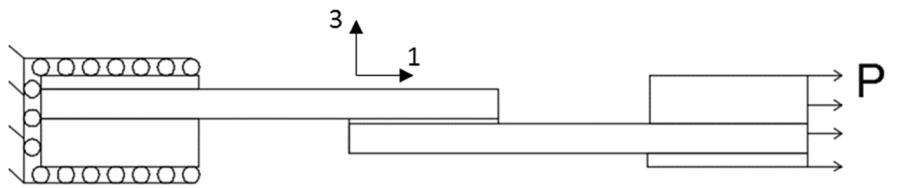

Table 1 Material properties of glass fibre/epoxy composite

\begin{tabular}{lcccccccc}
\hline$E_{11}(\mathrm{GPa})$ & $E_{22}(\mathrm{GPa})$ & $E_{33}(\mathrm{GPa})$ & $G_{12}(\mathrm{GPa})$ & $G_{13}(\mathrm{GPa})$ & $G_{23}(\mathrm{GPa})$ & $v_{12}$ & $v_{13}$ & $v_{23}$ \\
& & & & & & & & \\
\hline 36.85 & 15.35 & 3.35 & 9.87 & 7.90 & 3.69 & 0.4 & 0.3 & 0.32 \\
\hline
\end{tabular}


Table 2 Cohesive zone model parameters for adhesive layer

\begin{tabular}{cccccccc}
\hline & $G_{\mathrm{IIC}}(\mathrm{MPa} \cdot \mathrm{mm})$ & $T(\mathrm{MPa})$ & $S(\mathrm{MPa})$ & $C 1$ & $m 1$ & $C 2$ & $m 2$ \\
\hline 1.69 & 1.69 & 17.7 & 17.7 & 2.25 & 4.85 & 0.104 & 4.16 \\
\hline
\end{tabular}

Figure 10 S-N curve of adhesive joint (see online version for colours)

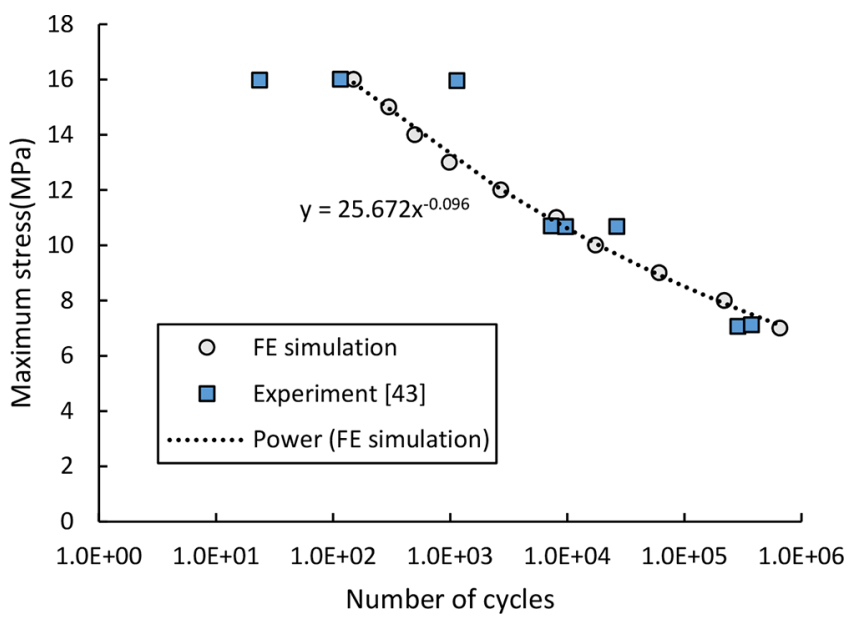

Figure 11 (a) Tensile strength along the length of adhesive joint and (b) Shear strength along the length of adhesive joint

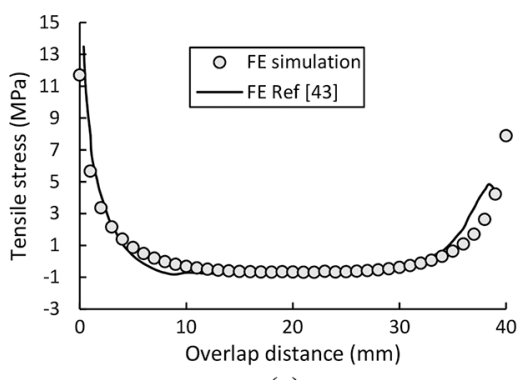

(a)

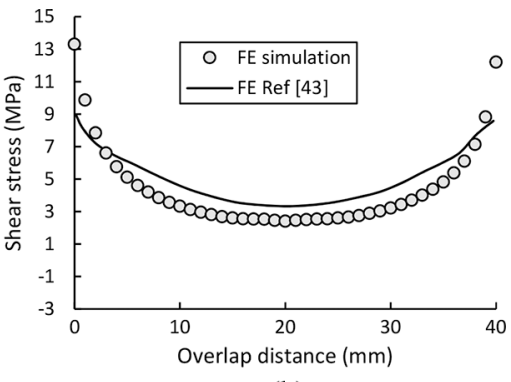

(b)

From Figure 10, it can be observed that the S-N curve from simulation matches experiment very well. Our proposed method along with mode-I and II Paris law parameters from the literature can predict the fatigue life of single-lap adhesive joint.

\subsection{Stepped-lap joint carbon/epoxy}

Like the previous simulation, this one is also to predict the S-N curve using FCGR, but on a stepped-lap joint. The experiment is done by Kim et al. (2004). In his paper, he studied the influence of lap length and step numbers on adhesive joint's static and fatigue strength. In our simulation, only a fixed lap length and two types of step numbers will be simulated. The two types of specimen geometry are illustrated in Figure 12, which has three steps and two steps. All the specimens have a width of $20 \mathrm{~mm}$. The specimens are 
made of carbon/epoxy composite, whose tensile modulus and Poisson's ratio are taken from Kim et al. (2004), as shown in Table 3. An orthotropic elastic material property is used in the simulation, and shear modulus is calculated using $G_{i j}=\frac{E_{i}}{4\left(1+v_{i j}\right)}+\frac{E_{j}}{4\left(1+v_{j i}\right)} \quad i, j=1,2,3$. From mode-I and II Paris law parameters are obtained and summarised in Table 4 along with the critical energy release rate. The specimen is load at two ends in tension at a frequency of $10 \mathrm{~Hz}$ and load ratio $R=0.1$. The S-N curve data from simulation and experiment are plotted in Figure 13. Again, our method is able to predict the S-N curve very well.

Figure 12 Geometry of stepped-lap joint specimen (a) 3 steps and (b) 2 steps

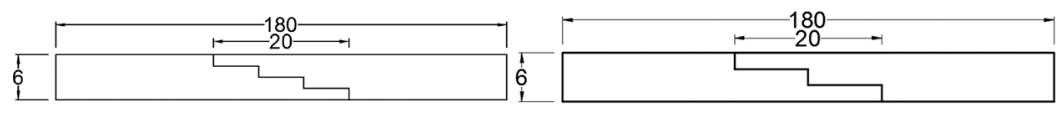

(a)

(b)

Table 3 Material properties of carbon/epoxy composite

\begin{tabular}{ccccccccc}
\hline$E_{11}(G P a)$ & $E_{22}(G P a)$ & $E_{33}(G P a)$ & $G_{12}(G P a)$ & $G_{13}(G P a)$ & $G_{23}(G P a)$ & $v_{12}$ & $v_{13}$ & $v_{23}$ \\
\hline 55.1 & 55.1 & 6.24 & 26.24 & 14.3 & 14.3 & 0.05 & 08 & 0.08 \\
\hline
\end{tabular}

Table 4 Cohesive zone model parameters for carbon/epoxy

\begin{tabular}{lccccccc}
\hline$G_{I C}(\mathrm{MPa} \cdot \mathrm{mm})$ & $G_{I I C}(\mathrm{MPa} \cdot \mathrm{mm})$ & $T(\mathrm{MPa})$ & $S(\mathrm{MPa})$ & $C 1$ & $m 1$ & $C 2$ & $m 2$ \\
\hline 0.27 & 1.02 & 18.6 & 25.25 & 10.5 & 5.81 & 0.1537 & 4.50 \\
\hline
\end{tabular}

Figure 13 S-N curve of stepped-lap joint (see online version for colours)

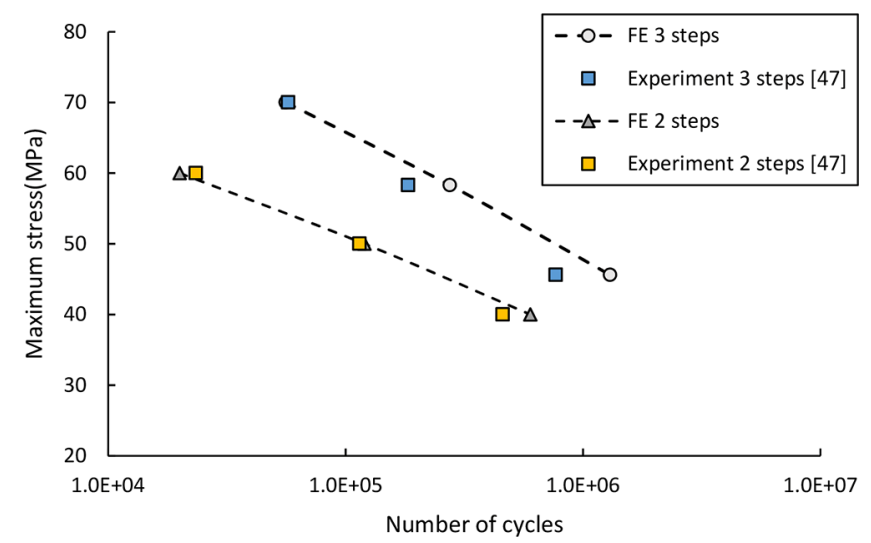




\section{Conclusion}

A method is presented to predict the fatigue life of adhesive joints. It combines FCGR and fatigue damage accumulation in the cohesive zone model. The method calculates the fatigue damage accumulation rate using the area changes under the traction-separation curve of cohesive law. The accumulated fatigue damage is then used to reduce the strength of the cohesive zone model. The method is implemented in LS-DYNA as a userdefined cohesive material. Implicit time integration is used for high cyclic loading, and viscous regularisation is applied to help achieve convergence

The method was validated on two adhesive joints under tensile fatigue loading. One validation is to obtain the S-N curve of a GFRE single-lap joint, and the other one is to obtain the S-N curve of carbon/epoxy stepped-lap joint. FCGR material parameters from the literature are used to predict the S-N curve done by separate experiments. The simulation results have good agreement with the experiment result and prove the fatigue life prediction ability of this method.

\section{References}

Asp, L.E., Sjögren, A. and Greenhalgh, E.S. (2001) 'Delamination growth and thresholds in a carbon/epoxy composite under fatigue loading', Journal of Composites, Technology and Research, Vol. 23, No. 2, pp.55-68.

Azari, S., Jhin, G., Papini, M. and Spelt, J. (2014) 'Fatigue threshold and crack growth rate of adhesively bonded joints as a function of load/displacement ratio', Composites Part A: Applied Science and Manufacturing, Vol. 57, pp.59-66.

Azari, S., Papini, M., Schroeder, J. and Spelt, J. (2010) 'The effect of mode ratio and bond interface on the fatigue behavior of a highly-toughened epoxy', Engineering Fracture Mechanics, Vol. 77, No. 3, pp.395-414.

Banea, M., da Silva, L., Carbas, R. and de Barros, S. (2016) 'Debonding on command of multi-material adhesive joints', The Journal of Adhesion, pp.1-15. http://dx.doi.org/ $10.1080 / 00218464.2016 .1199963$

Banea, M. and da Silva, L.F. (2009) 'Adhesively bonded joints in composite materials: An overview', Proceedings of the Institution of Mechanical Engineers, Part L: Journal of Materials Design and Applications, Vol. 223, No. 1, pp.1-18.

Banea, M.D. and da Silva, L.F. (2010) 'Static and fatigue behaviour of room temperature vulcanising silicone adhesives for high temperature aerospace applications. Statisches Verhalten und Dauerfestigkeitsanalyse von vulkanisierten Silikonklebstoffen für Luftfahrtanwendungen bei hohen Temperaturen', Materialwissenschaft und Werkstofftechnik, Vol. 41, No. 5, pp.325-335.

Barenblatt, G.I. (1962) 'The mathematical theory of equilibrium cracks in brittle fracture', Advances in Applied Mechanics, Vol. 7, No. 1, pp.55-129.

Bastani, P., Heywood, J.B. and Hope, C. (2012). US CAFE Standards: Potential for Meeting LightDuty Vehicle Fuel Economy Targets, 2016-2025. Massachusetts Institute of Technology, Cambridge, Massachusetts.

Benzeggagh, M. and Kenane, M. (1996) 'Measurement of mixed-mode delamination fracture toughness of unidirectional glass/epoxy composites with mixed-mode bending apparatus', Composites Science and Technology, Vol. 56, No. 4, pp.439-449.

Brown, E.N., White, S.R. and Sottos, N.R. (2006) 'Fatigue crack propagation in microcapsuletoughened epoxy', Journal of Materials Science, Vol. 41, No. 19, pp.6266-6273.

Camanho, P.P., Davila, C. and De Moura, M. (2003) 'Numerical simulation of mixed-mode progressive delamination in composite materials', Journal of Composite Materials, Vol. 37, No. 16, pp.1415-1438. 
Camanho, P.P. and Dávila, C.G. (2002) Mixed-mode decohesion finite elements for the simulation of delamination in composite materials, NASA/TM-2002-211737.

Casas-Rodriguez, J.P., Ashcroft, I.A. and Silberschmidt, V.V. (2008) 'Delamination in adhesively bonded CFRP joints: Standard fatigue, impact-fatigue and intermittent impact', Composites Science and Technology, Vol. 68, No. 12, pp.2401-2409.

Crisfield, M. (1983) 'An arc-length method including line searches and accelerations', International Journal for Numerical Methods in Engineering, Vol. 19, No. 9, pp.1269-1289.

Du, Y. and Shi, L. (2014) 'Effect of vibration fatigue on modal properties of single lap adhesive joints', International Journal of Adhesion and Adhesives, Vol. 53, pp.72-79.

Dugdale, D. (1960) 'Yielding of steel sheets containing slits', Journal of the Mechanics and Physics of Solids, Vol. 8, No. 2, pp.100-104.

Friedrich, K. and Almajid, A.A. (2013) 'Manufacturing aspects of advanced polymer composites for automotive applications', Applied Composite Materials, Vol. 20, No. 2, pp.107-128.

Grant, L., Adams, R. and da Silva, L.F. (2009) 'Experimental and numerical analysis of single-lap joints for the automotive industry', International Journal of Adhesion and Adhesives, Vol. 29, No. 4, pp.405-413.

Hadavinia, H., Kinloch, A., Little, M. and Taylor, A. (2003) 'The prediction of crack growth in bonded joints under cyclic-fatigue loading I. Experimental studies', International Journal of Adhesion and Adhesives, Vol. 23, No. 6, pp.449-461.

Hallquist, J.O. (2007) LS-DYNA keyword user's manual, Livermore Software Technology Corporation, 970.

Harper, P.W. and Hallett, S.R. (2008) 'Cohesive zone length in numerical simulations of composite delamination’, Engineering Fracture Mechanics, Vol. 75, No. 16, pp.4774-4792.

Harper, P.W. and Hallett, S.R. (2010) 'A fatigue degradation law for cohesive interface elementsdevelopment and application to composite materials', International Journal of Fatigue, Vol. 32, No. 11, pp.1774-1787.

Harris, J. and Fay, P. (1992) 'Fatigue life evaluation of structural adhesives for automative applications', International Journal of Adhesion and Adhesives, Vol. 12, No. 1, pp.9-18.

Jacob, G.C., Fellers, J.F., Simunovic, S. and Starbuck, J.M. (2002) 'Energy absorption in polymer composites for automotive crashworthiness', Journal of Composite Materials, Vol. 36, No. 7, pp.813-850.

Jacob, G.C., Fellers, J.F., Starbuck, J.M. and Simunovic, S. (2004) 'Crashworthiness of automotive composite material systems', Journal of Applied Polymer Science, Vol. 92, No. 5, pp.3218-3225.

Kadioglu, F. and Adams, R.D. (2015) 'Flexible adhesives for automotive application under impact loading', International Journal of Adhesion and Adhesives, Vol. 56, pp.73-78.

Kim, J., Park, B. and Han, Y. (2004) 'Evaluation of fatigue characteristics for adhesively-bonded composite stepped lap joint', Composite Structures, Vol. 66, No. 1, pp.69-75.

Kim, M., Yan, J., Joo, K., Pandey, J.K., Kang, Y. and Ahn, S. (2013) 'Synergistic effects of carbon nanotubes and exfoliated graphite nanoplatelets for electromagnetic interference shielding and soundproofing', Journal of Applied Polymer Science, Vol. 130, No. 6, pp.3947-3951.

Kuczmaszewski, J. and Bylica, T. (2006) 'Fundamentals of metal-metal adhesive joint design, Lublin University of Technology', Polish Academy of Sciences, Lublin Branch, Lublin.

Kumar, S., Sridhar, I., Sivashanker, S., Osiyemi, S. and Bag, A. (2006) 'Tensile failure of adhesively bonded CFRP composite scarf joints', Materials Science and Engineering: B, Vol. 132, No. 1, pp.113-120.

Landry, B. and LaPlante, G. (2012) 'Modeling delamination growth in composites under fatigue loadings of varying amplitudes', Composites Part B: Engineering, Vol. 43, No. 2, pp.533-541. 
Liu, Q., Lin, Y., Zong, Z., Sun, G. and Li, Q. (2013) 'Lightweight design of carbon twill weave fabric composite body structure for electric vehicle', Composite Structures, Vol. 97, pp.231-238.

Mansor, M.R., Sapuan, S., Hambali, A., Zainudin, E.S. and Nuraini, A. (2014a) 'Materials selection of hybrid bio-composites thermoset matrix for automotive bumper beam Applicationusing Topsis method', Advances in Environmental Biology, Vol. 8, No. 8, pp.3138-3442.

Mansor, M.R., Sapuan, S., Zainudin, E.S., Nuraini, A. and Hambali, A. (2014b) 'Conceptual design of kenaf fiber polymer composite automotive parking brake lever using integrated TRIZMorphological chart-Analytic hierarchy process method', Materials \& Design, Vol. 54, pp.473-482.

O'Brien, T., Johnston, W.M, and Toland, G.J. (2010) Mode II interlaminar fracture toughness and fatigue characterization of a graphite epoxy composite material, L-19898; NASA/TM-2010216838; NF1676L-10105.

Pang, J., Du, Y., Wu, K., Hu, P. and Li, W. (2013) 'Fatigue analysis of adhesive joints under vibration loading', The Journal of Adhesion, Vol. 89, No. 12, pp.899-920.

Parliament, E. (2009) 'Setting emission performance standards for new passenger cars as part of the Community's integrated approach to reduce $\mathrm{CO}_{2}$ emissions from light-duty vehicles', Regulation (EC) No, Vol. 443, No. 2009, p.23.

Pirondi, A. and Nicoletto, G. (2004) 'Fatigue crack growth in bonded DCB specimens', Engineering Fracture Mechanics, Vol. 71, No. 4, pp.859-871.

Pugno, N., Ciavarella, M., Cornetti, P. and Carpinteri, A. (2006) 'A generalized Paris' law for fatigue crack growth', Journal of the Mechanics and Physics of Solids, Vol. 54, No. 7, pp.1333-1349.

Quaresimin, M. and Ricotta, M. (2006) 'Fatigue behaviour and damage evolution of single lap bonded joints in composite material', Composites Science and Technology, Vol. 66, No. 2, pp.176-187.

Roe, K. and Siegmund, T. (2003) 'An irreversible cohesive zone model for interface fatigue crack growth simulation', Engineering Fracture Mechanics, Vol. 70, No. 2, pp.209-232.

Svensson, M., Mark, A., Edelvik, F., Kressin, J., Bolin, R., Segerdahl, D., Carlson, J.S., Wahlborg, P. and Sundbäck, M. (2016) 'Process simulation and automatic path planning of adhesive joining', Procedia CIRP, Vol. 44, pp. 298-303.

Tang, J., Sridhar, I. and Srikanth, N. (2013) 'Static and fatigue failure analysis of adhesively bonded thick composite single lap joints', Composites Science and Technology, Vol. 86, pp.18-25.

Turon, A., Camanho, P.P., Costa, J. and Dávila, C. (2006) 'A damage model for the simulation of delamination in advanced composites under variable-mode loading', Mechanics of Materials, Vol. 38, No. 11, pp.1072-1089.

Turon, A., Costa, J., Camanho, P. and Dávila, C. (2007) 'Simulation of delamination in composites under high-cycle fatigue', Composites Part A: applied science and manufacturing, Vol. 38, No. 11, pp.2270-2282.

Varvani-Farahani, A., Haftchenari, H. and Panbechi, M. (2007) 'An energy-based fatigue damage parameter for off-axis unidirectional FRP composites', Composite Structures, Vol. 79, No. 3, pp.381-389.

Vucko, F., LeBozec, N., Thierry, D., Weber, B., Dosdat, L., Luckeneder, G., Bschorr, T., Rother, K., Sciaboni, C. and Sczepanski, J. (2016) 'Combined corrosion and fatigue performance of joined materials for automotive applications', Materials and Corrosion, Vol. 67, No. 11, pp.1143-1151.

Yu, H., Olsen, J.S., Olden, V., Alvaro, A., He, J. and Zhang, Z. (2016) 'Viscous regularization for cohesive zone modeling under constant displacement: an application to hydrogen embrittlement simulation', Engineering Fracture Mechanics, Vol. 166, pp.23-42. 


\section{Appendix A. Keywords that controls convergence in LS-DYNA input file}

\begin{tabular}{|c|c|c|c|c|c|c|c|}
\hline \multicolumn{8}{|c|}{ *CONTROL_IMPLICIT_AUTO } \\
\hline Iauto & Iteopt & Itewin & Dtmin & Dtmax & Dtexp & Kfail & Kcycle \\
\hline 1 & 10 & 10 & 0.0 & 0.1 & 0.0 & 0 & 0 \\
\hline \multicolumn{8}{|c|}{ *CONTROL_IMPLICIT_DYNAMICS } \\
\hline Imass & Gamma & Beta & Tdybir & Tdydth & Tdybur & Irate & \\
\hline 1 & 0.6 & 0.38 & 0.0 & $1.0 \mathrm{E} 28$ & $1.0 \mathrm{E} 28$ & 0 & \\
\hline \multicolumn{8}{|c|}{ *CONTROL_IMPLICIT_GENERAL } \\
\hline Imflag & Dt0 & Imform & Nsbs & Igs & Cnstn & Form & Zero_v \\
\hline 1 & 1 & 2 & 1 & 1 & 0 & 0 & 0 \\
\hline \multicolumn{8}{|c|}{ *CONTROL_IMPLICIT_SOLUTION } \\
\hline Nsolvr & Ilimit & Maxref & Dctol & Ectol & Rctol & Lstol & Abstol \\
\hline 12 & 6 & 30 & 0.001 & 0.01 & $1 \mathrm{e} 10$ & 0.9 & $1 \mathrm{e}-10$ \\
\hline Dnorm & Diverg & Istif & Nlprint & Nlnorm & D3itctl & Cpchk & \\
\hline 1 & 1 & 1 & 0 & 2 & 0 & 0 & \\
\hline Arcctl & Arcdir & Arclen & Arcmth & Arcdmp & Arcpsi & Arcalf & Arctim \\
\hline 0 & 0 & 0.0 & 1 & 2 & 0 & 0 & 0 \\
\hline Lsmtd & Lsdir & Irad & Srad & Awgt & Sred & & \\
\hline 4 & 2 & 0.0 & 2.0 & 1.0 & 0.0 & & \\
\hline \multicolumn{8}{|c|}{ *CONTROL_IMPLICIT_SOLVER } \\
\hline Lsolvr & Lprint & Negev & Order & Drcm & Drcprm & Autospc & Autotol \\
\hline 5 & 1 & 2 & 0 & 4 & 0 & 1 & 0 \\
\hline Lscpack & Mtxdmp & & & & & & \\
\hline 2 & 0 & & & & & & \\
\hline
\end{tabular}

